\title{
La calma antes de la tempestad. Carlistas y neocatólicos en el País Valenciano entre 1849 y 1868
}

\author{
The Calm before the Storm. Carlist and Neocatholics in the \\ Valencian country between 1849 and 1868
}

\author{
Antonio Caridad Salvador \\ IES Abastos de Valencia
}

Recibido: 13-XII-2011

Aceptado: 27-XI-2012

\section{Resumen}

Entre 1849 y 1868 el carlismo valenciano vivió una época oscura, en la que su actividad fue muy reducida, dados los fracasos de sus anteriores revueltas y el apoyo al moderantismo de muchos antiguos carlistas. Al mismo tiempo tanto surgía un grupo absolutista que aceptaba como reina a Isabel II y que llegó a entrar en el juego parlamentario. Se trataba de los monárquicos puros (o neocatólicos), que defendían una vuelta a un régimen más tradicional pero sin buscar un cambio de monarca. A partir de 1865, con el reconocimiento del Estado italiano, empezará la convergencia entre estas dos corrientes.

Palabras clave: Carlismo, Liberalismo, Neocatólicos, Aparisi y Guijarro.

\begin{abstract}
Between 1849 and 1868 the Valencian carlism lived a dark age, in which its activity was very small, due to the failures of its previous revolts and the support to moderantism of many former carlists. At the same time, it emerged an absolutist group which accepted Elizabeth II as queen and that took part in the parliamentary activity. They were the pure monarchics (or neocatholics), that defended a return to a more traditional régime, without demanding a change in the monarchy. Starting on 1865, with the recognition of the Italian State, it began the convergence between both political tendencies.
\end{abstract} Keywords: Carlism, Liberalism, Neocatholics, Aparisi y Guijarro. 


\section{El carlismo en crisis}

La revuelta de los matiners confirmó el escaso apoyo que los partidarios de don Carlos tenían por esas fechas en las comarcas del norte valenciano, que antaño habían sido fuertemente carlistas. En esta ocasión la rebelión no se produjo hasta que llegaron partidas procedentes de Cataluña y a una escala tan pequeña que fue aplastada en pocos meses. Esto podría indicarnos que la mayoría de la población del Maestrazgo sólo dio un apoyo coyuntural al carlismo en los años 30. Sus convicciones en este sentido no debían ser muy fuertes y si lucharon contra los liberales lo hicieron para poder sobrevivir en una época de crisis económica, porque habían sido reclutados a la fuerza o para vengar algún exceso cometido por los liberales contra ellos o contra sus familiares. Pero la guerra fue tan larga y trajo tanta muerte y destrucción, que acabó creando un extendido deseo de paz entre los valencianos. Además, el carlismo también quedó desprestigiado por la contienda, ya que las fuerzas del pretendiente cometieron numerosos excesos, a menudo contra sus propios partidarios. Si a esto sumamos que la revolución liberal no perjudicó a la mayoría de los campesinos y que los carlistas más exaltados estaban muertos o exiliados, podemos entender el descenso en el apoyo al legitimismo a partir de 1840.

Pero los partidarios de don Carlos no se dieron por enterados y durante las décadas siguientes continuaron intentando revueltas y conspiraciones, que se saldaron todas ellas con un absoluto fracaso. Creían que la población seguía siéndoles fiel y que bastaba con crear algunas partidas o con sublevar alguna unidad del ejército, para que el pueblo tomase las armas entusiasmado. Sin embargo, las cosas habían cambiado y la inmensa mayoría de la gente ya sólo quería vivir en paz, sin importarles demasiado quien fuera rey de España, mientras no se tocase su forma de vida. Esto se hizo patente cuando el capitán general de Valencia, Juan Villalonga, que había aplastado revueltas carlistas en 1844 y 1848, inició una gira por la Plana Baja y el Maestrazgo. Así pues, en junio de 1850 el militar liberal entró en Villarreal, donde fue recibido con inequívocas muestras de entusiasmo, pese a la pobreza en que la sequía había sumido a la población. En esta ocasión hubo repique de campanas, casas con colgaduras, vítores, aclamaciones y obsequios, algo que no se había visto en dicha localidad durante la regencia de Maria Cristina. Lo mismo ocurrió poco después en San Mateo, donde mucha gente salió a recibirle y se levantaron arcos en su honor. El pueblo estaba entusiasmado y los campesinos se acercaban para saludarle y ofrecerle su cariño y agradecimiento por la paz que les había traído ${ }^{1}$. Esto se repitió en octubre del año siguiente, cuando el nuevo capitán general, Valentín

1. Diario Mercantil de Valencia, 30-VI y 2-VII-1850. 
Cañedo, recorrió durante 23 días el Maestrazgo, siendo recibido en todos los pueblos con festejos en su honor, sin que se produjera ningún incidente ${ }^{2}$.

\section{Neocatolicismo y carlismo. Ideas parecidas por caminos diferentes}

Mientras el carlismo se debilitaba aparecían los monárquicos puros (también llamados neocatólicos), que querían la vuelta a una monarquía tradicional, pero que aceptaban como reina a Isabel II. Ninguno de sus líderes había destacado antes en el seno del carlismo, sino que procedían del liberalismo más conservador, desencantado con la labor de los gobiernos moderados. Sus principales dirigentes eran personas de orden que aborrecían la violencia y que, aunque podían compartir muchas cosas con el carlismo, rechazaban su recurso constante a la lucha armada. Hay que tener en cuenta que para ciertas elites hispanas la violencia carlista (ejercida a menudo por masas indisciplinadas) podía ser más inquietante que las reformas liberales ${ }^{3}$.

A nivel valenciano el neocatolicismo empezó a funcionar en marzo de 1850 cuando la oposición conservadora a Narváez decidió presentar su primera candidatura, que no tuvo ningún éxito. De hecho, en los comicios para diputado provincial en el partido de Morella sólo consiguieron un voto, frente a los 54 del candidato gubernamental ${ }^{4}$. Después de esto se produjo un debate sobre si presentarse o no a las elecciones al Congreso de ese año, a lo que respondió La Esperanza dejando libertad de acción. Hay que tener en cuenta que este periódico era el representante oficioso del partido carlista, lo que nos indica la cercanía de los monárquicos puros a los partidarios de don Carlos. Volviendo al tema anterior, al final se decidió apoyar a José Polo y Borrás, candidato cercano a sus ideas y que se presentaba simultáneamente en Nules y en Morella ${ }^{5}$. De ideas parecidas eran Fermín Gonzalo Morón, José Vallterra y Ramón Calvo, que formaban la oposición conservadora a Narváez. Estos individuos se presentaron en la provincia de Valencia con muy poco éxito, ya que entre los tres sólo consiguieron 46 votos (casi todos en la capital del Turia), frente a 3.318 de los candidatos moderados ${ }^{6}$.

Pero seguía habiendo división de opiniones, por lo que en abril de 1851 se celebró una nueva reunión de monárquicos puros, esta vez en casa del marqués

2. Diario Mercantil de Valencia, 16-X-1851.

3. ROMEO MATEO, $M^{a}$ Cruz, "¿Qué es ser neocatólico? La crítica antiliberal de Aparisi y Guijarro", en AA.VV, "Por Dios, por la patria y el rey". Las ideas del carlismo, IV Jornadas de Estudios del Carlismo, Estella, Gobierno de Navarra, 2010, pp. 155-157.

4. Diario Mercantil de Valencia, 3-III-1850.

5. Diario Mercantil de Valencia, 18 y 21-VIII-1850.

6. Boletín Oficial de Valencia, 3-IX-1850. 
de Cáceres, para decidir sobre la conducta a seguir en las elecciones siguientes ${ }^{7}$. No sabemos lo que decidieron al final, pero sí que siete meses después se presentó a las elecciones municipales un miembro de este partido, el prestigioso abogado Antonio Aparisi y Guijarro, por el segundo distrito de la ciudad de Valencia. También en esta ocasión el resultado fue desastroso, ya que sólo obtuvo un voto, por lo que quedó muy lejos de resultar elegido 8 . El mismo resultado se repitió en noviembre de 1853, cuando dicho político volvió a presentarse a los comicios locales ${ }^{9}$. Esto no es de extrañar si tenemos en cuenta que sus potenciales apoyos, las personas acomodadas que querían un régimen católico y una monarquía tradicional, se encontraban muy a gusto con los gobiernos ultraconservadores de Bravo Murillo y de Luis José Sartorius, que dirigieron los destinos de España entre 1851 y 1854.

En este grupo estaba Miguel Vicente Almazán, calificado como el Donoso Cortés valenciano, que en 1852 publicó unos Estudios filosóficos sobre legislación. Este libro es muy importante, ya que se puede considerar como la reacción de algunos sectores de la burguesía valenciana ante las revoluciones de 1848 . Así pues, para evitar el avance del socialismo y del liberalismo progresista, empezó a haber sectores del liberalismo más conservador que empezaron a decantarse por un régimen autoritario basado en el tradicionalismo católico ${ }^{10}$. No obstante, mientras el gobierno de España defendió estas ideas el neocatolicismo político fue muy débil, ya que sus potenciales electores no veían la necesidad de un grupo parlamentario propio.

Algo parecido sucedía con el carlismo, que seguía perdiendo importancia, debido al conservadurismo del régimen moderado y al concordato de 1851, que arregló las relaciones entre el estado español y el papado. De esta manera, muchas personas de orden y con fuertes ideas religiosas no veían ya motivos para oponerse a los gobiernos isabelinos, que habían anulado o paralizado muchas de las reformas de los progresistas. Pese a ello, los liberales todavía veían el legitimismo como una amenaza latente, como nos muestran varios ejemplos. El primero de ellos data de enero de 1854, cuando la prensa tuvo que desmentir que hubiera habido intentonas carlistas en el Maestrazgo ${ }^{11}$. Siete meses más tarde corrió la voz de que por el término de Alcalá de Chivert circulaban siete hombres armados, pero no se les pudo encontrar, después de varias batidas ${ }^{12}$.

7. Diario Mercantil de Valencia, 16-IV-1851.

8. Diario Mercantil de Valencia, 19-VIII-1849, 3 y 4-IX-1851.

9. Diario Mercantil de Valencia, 2, 3 y 4-IX-1853.

10. MARTÍNEZ GALLEGO, Francesc Andreu, Conservar progresando. La Unión Liberal (1856-1868), Valencia, UNED, 2001, pp. 78 y 79.

11. Diario Mercantil de Valencia, 11-I-1854.

12. Diario Mercantil de Valencia, 14-VIII-1854. 
Los que sí que operaron durante un tiempo fueron veinte "latro-facciosos" procedentes de Aragón, adonde regresaron en agosto después de robar algunas diligencias $^{13}$. Con el término "latro-faccioso" la prensa liberal solía referirse a bandidos que habían sido combatientes carlistas y que utilizaban las ideas políticas como excusa para delinquir.

Por otra parte, ese verano triunfó una revolución progresista que devolvió el poder a Espartero, lo que llevó a los carlistas a pensar que había llegado su momento. Por ello Cabrera, uno de los principales jefes tradicionalistas, entró en contacto con el coronel Díez de Mogrovejo, que había pertenecido a las fuerzas carlistas hasta que se acogió al convenio de Vergara en 1839. Quince años después mandaba el regimiento de infantería de Asturias, con sede en Valencia, lo que aprovechó para ofrecer a Cabrera las plazas de Sagunto, Alicante y Morella, guarnecidas por fuerzas de aquel regimiento. Además, comunicó al jefe carlista que el comandante de un batallón de la milicia nacional de Valencia estaba dispuesto a secundar un hipotético alzamiento ${ }^{14}$.

Durante los meses siguientes las intrigas continuaron. En enero de 1855 Manuel José Riambau, con especial comisión del conde de Samitier, marchó a Valencia y a Madrid para entablar contacto con personas que apoyaban al conde de Montemolin ${ }^{15}$. Y en Liria el comandante Bordanova, que residía allí, estaba en contacto con exiliados de Francia para promover un alzamiento. De hecho escribió a un amigo, llamado Felipe Ruiz, diciéndole le esperaba con impaciencia y que "la cosa" iría bien. Este individuo era natural de Foyos y había servido en la guardia real, de donde pasó a la facción en 1835. Posteriormente participó en la revuelta de los matiners, antes de regresar al exilio en Burdeos, con el grado de capitán del ejército carlista ${ }^{16}$.

También se producían maquinaciones en Morella, mientras se realizaba atractivas ofertas a muchos oficiales del ejército ${ }^{17}$. Los partidarios de don Carlos habían prometido ascensos a algunos militares con destino en la plaza para que abrieran las puertas de la población a 4.000 paisanos, que acudirían de todos los puntos del Maestrazgo. Estos invasores sorprenderían a la guarnición del castillo y matarían al capitán Mallen (que mandaba dicho punto), así como al mayor

13. Diario Mercantil de Valencia, 28-VIII-1854.

14. PIRALA CRIADO, Antonio, Historia contemporánea. Segunda parte de la guerra civil. Anales desde 1843 hasta el fallecimiento de don Alfonso XII, Madrid, Felipe González Rojas editor, 1892-1906, v. 1, pp. 670 y 671. FERRER, Melchor, ACEDO, José y TEJERA, Domingo, Historia del tradicionalismo español, Sevilla, Ediciones Trajano y Editorial Católica Española, 1941-1960, v. 20, p. 169.

15. PIRALA CRIADO, Antonio, Historia contemporánea..., v. 1, p. 671.

16. Archivo General del Ministerio de Asuntos Exteriores y Cooperación, legajo H 2843.

17. Diario Mercantil de Valencia, 20-I-1855. 
de plaza y a alguna otra persona, antes de proclamar rey a Carlos VI. Pero el plan fue descubierto en marzo, siendo juzgados el primer ayudante de plaza, un tal Estévanez, así como el secretario del gobierno militar, que eran los jefes de la conspiración ${ }^{18}$. Tras estos hechos el gobernador de Morella salió con una columna, mientras que otra fuerza (compuesta por ocho compañías) realizó varias marchas por el Maestrazgo, en busca de posibles cómplices en el exterior ${ }^{19}$.

Pero este no fue el único intento de los carlistas. El plan de Valencia fue abortado cuando el capitán Huet, del regimiento de carabineros de la reina, fue detenido y llevado a prisión ${ }^{20}$. Díez de Mogrovejo no parece que fuera arrestado, probablemente porque decidiría paralizar los preparativos, por miedo a sufrir la misma suerte. En cuanto a Bordanova, debió ser descubierto, ya que no llegó a tomar las armas y poco después marchó al exilio en Francia ${ }^{21}$. Donde sí se produjeron síntomas de desorden fue en Orihuela, lo que llevó a movilizar a la milicia y a cambiar totalmente el ayuntamiento ${ }^{22}$.

El 22 de mayo estalló una revuelta carlista en Aragón, que animó a los tradicionalistas valencianos a reanudar sus preparativos. Las autoridades recibieron informes de que dos antiguos capitanes carlistas habían convencido a varios sargentos para que se rebelaran y ocuparan así los castillos de Peñíscola y Sagunto. Se decía que el alzamiento contaba con el apoyo de algunos soldados y que se pondría al frente Antonio Santapau, antiguo vocal de la junta carlista de Cabrera ${ }^{23}$. Al mismo tiempo, en algunos puntos del Maestrazgo se apreciaron síntomas de preparativos carlistas, por lo que el capitán general de Valencia declaró en estado de guerra todo ese territorio. Al final todo esto quedó en nada y, al ver que no había peligro alguno, el gobernador de Morella salió con una columna hacia el Bajo Aragón, donde se había producido un levantamiento carlista ${ }^{24}$.

Mientras tanto, en Denia algunos sargentos planeaban apoderarse del castillo para proporcionar una fortaleza a los rebeldes, pero el movimiento fue descubierto en junio, siendo sus autores detenidos. Probablemente estos militares estaban en contacto con los carlistas de Orihuela, que también estaban conspirando por esas fechas ${ }^{25}$. De hecho, en esa ciudad fueron detenidas 35

18. Diario Mercantil de Valencia, 18-III-1855. PIRALA CRIADO, Antonio, Historia contemporánea..., v. 1, p. 670.

19. FERRER, Melchor, ACEDO, José y TEJERA, Domingo, Historia del tradicionalismo... v. 20 , pp. 171 y 172 .

20. Ibid., p. 171.

21. Archivo General Militar de Segovia, primera sección, legajo B-3466.

22. Diario Mercantil de Valencia, 24-III-1855.

23. Archivo de la Diputación Provincial de Zaragoza, vigilancia, caja XVI-1189.

24. La Libertad, 1-VI-1855.

25. Diario Mercantil de Valencia, 14-VI-1855. 
personas más por participar en una conjura montemolinista. Entre ellos se encontraba un canónigo de la catedral, así como Ambrosio Chillida, dominico de la orden de predicadores y que había estado en las filas de Cabrera en la anterior guerra civil. Este último fue condenado a doce años de presidio y casi todos los demás a ocho años, salvo cuatro o cinco, que salieron en libertad. También se vio implicado Antonio Simeón Dimas, que tenía la dignidad de maestrescuela, al que se le siguió causa por separado ${ }^{26}$.

Tras estos hechos el alzamiento carlista valenciano se desinfló, antes de haber llegado a producirse. Y aunque en septiembre se presentaron en Morella algunos agentes legitimistas, con dinero para promover una nueva sublevación, regresaron de allí sin obtener ningún resultado. Los militares ya estaban escarmentados y la población civil tampoco quería saber nada de nuevas guerras ${ }^{27}$.

Mejor les iba a los monárquicos puros, que empezaron a recibir apoyos de los sectores más conservadores del moderantismo, asustados por la experiencia del Bienio Progresista. De esta manera, en septiembre de 1856 cosecharon su primer éxito electoral, al colocar a Aparisi y Guijarro como regidor en Valencia ${ }^{28}$. Animado por este éxito, seis meses después se presentó a las elecciones a Cortes por el distrito de Serranos. Esta vez no fue elegido, pero quedó sexto con 82 votos, el mejor resultado que habían obtenido hasta entonces los neocatólicos ${ }^{29}$.

Estos éxitos han llevado a María Begoña Urigüen a afirmar que el neocatolicismo surgió a consecuencia de las reformas del Bienio Progresista. Como hemos podido ver anteriormente, esto no es cierto, pues desde 1850 estaban presentando candidaturas y reuniéndose como un grupo político más, al menos en Valencia. Lo que sí que sucedió es que la experiencia del bienio, en el que se debatió por primera vez sobre la libertad de cultos y sobre la confesionalidad del estado (al tiempo que se llevó a cabo una nueva desamortización) llevó a los moderados más integristas a apoyar a los monárquicos puros, a los que veían como los mejores defensores de la religión ${ }^{30}$. De esta manera, un grupo hasta entonces insignificante empezó a tener un protagonismo cada vez mayor.

Por estas fechas José Polo consiguió ser elegido diputado a Cortes por el distrito de Lucena del Cid (Castellón). Otro diputado de ideas ultracatólicas era Manuel Lasala, elegido por Morella, y que también destacó por su defensa

26. Diario Mercantil de Valencia, 14-VI-1855. CARPIZO BERGARECHE, Esperanza, La Esperanza carlista (1844-1874), Madrid, Editorial Actas, 2008, p. 649.

27. Diario Mercantil de Valencia, 5-IX-1855.

28. Diario Mercantil de Valencia, 13-IX y 25-X-1856.

29. Diario Mercantil de Valencia, 9, 24, 25 y 26-III-1857.

30. URIGÜEN GONZÁLEZ, María Begoña, Origen y desarrollo de la derecha española en el siglo XIX, Madrid, Universidad Complutense, 1981, pp. 222, 227, 233 y 1136. 
de la religión. Ambos fueron los dos únicos diputados valencianos que en 1857 votaron a favor de una enmienda de Cándido Nocedal a la ley de educación de Claudio Moyano. Dicha propuesta, que recibió el apoyo a los sectores más conservadores de la cámara, pretendía aumentar el control de la educación por parte de la iglesia, impidiendo así cualquier intento de secularizarla ${ }^{31}$.

\section{Antonio Aparisi y Guijarro}

En marzo de ese año una parte del partido moderado, liderado por el marqués de Cáceres, concurrió a las elecciones a Cortes bajo el nombre de monárquicosindependientes. Era gente muy conservadora y el periódico El Edetano llegó a afirmar que eran absolutistas y que en sus filas había elementos próximos al carlismo. Junto a ellos iban los neocatólicos (de ideas muy similares), que presentaron de nuevo a Aparisi y Guijarro como candidato por el distrito de Serranos, en Valencia. Pese a estos apoyos tampoco esta vez pudo ser elegido, ya que sólo consiguió 158 votos frente a 230 del moderado conde de Almodóvar, en unas elecciones en las que se cometieron coacciones por parte de las autoridades ${ }^{32}$.

Entonces el neocatólico debió pensar que le faltaba un órgano de difusión de sus ideas, a fin de tener más éxito en los siguientes comicios. Por ello se puso al frente de El Pensamiento de Valencia, publicación financiada por el marqués de Cáceres, José María Vallterra y otros políticos ultraconservadores, en la que Aparisi expuso sus ideas monárquicas y religiosas ${ }^{33}$. Esta revista semanal, en la que colaboraba también León Galindo Vera, se inspiraba en los mismos principios que había defendido Jaime Balmes en El Pensamiento de la Nación ${ }^{34}$. Por una parte Aparisi se declaraba opuesto al liberalismo y al parlamentarismo decimonónico ${ }^{35}$. Y al mismo tiempo se declaraba partidario de las libertades provinciales, de las oposiciones para acceder a la función pública y de que se dictaran leyes de caridad para los pobres. Estas ideas no eran del agrado de las autoridades, por lo que el número 7 fue secuestrado, por orden del gobernador de Valencia. El propietario de la revista, Vicente Linares, reclamó contra esta medida, pero acabó siendo multado con 50 duros. Hechos como este se repitieron más tarde, lo que obligó a la revista a echar el cierre el 30 de mayo de 1858 , tras dos secuestros y tres multas ${ }^{36}$.

31. Ibid., pp. 287-296.

32 . MARTÍNEZ GALLEGO, Francesc Andreu, Conservar progresando..., pp. 42-45.

33. FERRER, Melchor, ACEDO, José y TEJERA, Domingo, Historia del tradicionalismo..., v. 21, p. 85. MARTÍNEZ GALLEGO, Francesc Andreu, Conservar progresando..., p. 78.

34. URIGÜEN GONZÁLEZ, María Begoña, Origen y desarrollo..., p. 362.

35. MARTÍNEZ GALLEGO, Francesc Andreu, Conservar progresando..., p. 78.

36. FERRER, Melchor, ACEDO, José y TEJERA, Domingo, Historia del tradicionalismo... v. 21, p. 85. 
Mientras tanto Aparisi y Guijarro no conseguía mejorar su resultado anterior, ya que en las elecciones de marzo de 1858 quedó otra vez segundo en el distrito de Serranos, con 106 votos a su favor ${ }^{37}$. Siete meses después el partido monárquico puro presentó por Orihuela a José María Maya, abogado de La Coruña, como candidato a Cortes. Algunos periodistas liberales se felicitaron entonces de que el partido absolutista probase sus fuerzas en estas elecciones, pese a la política de retraimiento anunciada por los órganos de la liga ${ }^{38}$. Sin embargo, hubo otros que afirmaban que estos candidatos no eran más que carlistas camuflados, más flexibles e hipócritas que los emigrados, que se habían disfrazado con la careta monárquica para ocultar mejor sus intenciones ${ }^{39}$.

Sea como fuere, la verdad es que Aparisi y Guijarro era una figura en ascenso. En octubre se presentó de nuevo por el distrito de Serranos y esta vez fue por fin elegido diputado ${ }^{40}$. Este éxito se debió a que cada vez era más conocido, debido a su paso por El Pensamiento de Valencia. Pero también a que su antiliberalismo había encontrado eco entre algunos sectores conservadores valencianos, preocupados por el impacto de las revoluciones europeas de 1848 y por el miedo a que se repitiese el bienio progresista de $1854-1856^{41}$. De esta manera, nuestro personaje se convirtió en el único representante en el Congreso de la fracción monárquica pura ${ }^{42}$, defendiendo algo parecido a un absolutismo ilustrado. De hecho, se declaró favorable a la autonomía regional y a la existencia de unas Cortes elegidas en unas elecciones limpias, al tiempo que idealizaba una monarquía tradicional, en la que los monarcas defendían al pueblo de los abusos de los poderosos ${ }^{43}$. Sus ideas, avanzadas en algunos aspectos, causaron la sorpresa de la prensa liberal, que le reconoció su honradez y su buena oratoria ${ }^{44}$. Al mismo tiempo, Aparisi compaginaba la política con el periodismo, ya que escribía artículos en La Esperanza con los pseudónimos "El solitario" y "El Rústico". Además, era redactor de La Restauración y de otras publicaciones monárquico-religiosas ${ }^{45}$.

Este ascenso del tradicionalismo hizo temer a los liberales que se estuvieran preparando nuevos alzamientos carlistas. Esto les llevó a imaginar complots

37. Diario Mercantil de Valencia, 20-III-1858.

38. Diario Mercantil de Valencia, 22-X-1858.

39. Diario Mercantil de Valencia, 29-VII-1858.

40. Diario Mercantil de Valencia, 28, 29, 30-X y 4, 11-XI-1858.

41. ROMEO MATEO, Ma Cruz, "¿Qué es ser...", p. 149.

42. Diario Mercantil de Valencia, 13-II-1859.

43. VILLACORTA NÚÑEZ, Jose Luis, La derrota intelectual del carlismo. Aparisi y Guijarro frente al siglo, Bilbao, Editorial Desclee de Brouwer S.A, 1990, pp. 209, 211, 253, 264, 265 y 267.

44. Diario Mercantil de Valencia, 2-III-1859.

45. CARPIZO BERGARECHE, Esperanza, La Esperanza..., p. 788. 
inexistentes, como el que se sobreseyó en Orihuela, en febrero de $1857^{46}$. Dos meses después volvieron a correr rumores en este sentido ${ }^{47}$ y en junio hubo otros similares en el Maestrazgo, estos también sin ningún fundamento ${ }^{48}$. Para intentar reducir el apoyo al pretendiente, el gobierno concedió un nuevo indulto, que afectaba a los que habían tomado parte en las insurrecciones carlistas de los dos años anteriores ${ }^{49}$.

\section{Rebeliones carlistas}

Tras varios años inactivos, el 27 de mayo de 1859 se produjo una intentona de verdad, aunque a una escala tan pequeña que era totalmente imposible que triunfara. Todo empezó por la mañana de ese día, cuando abandonaron Valencia dos carruajes, que transportaban entre 15 y 20 personas. El jefe del grupo era Pascual Gascón, antiguo oficial carlista, que al llegar al término de Manises ordenó distribuir las armas que llevaban en un cofre. Acto seguido se dirigieron hacia Chiva, pero debieron ser vistos por algún viajero, ya que el alcalde se enteró y reunió una fuerte patrulla para defender la población. Entonces los carlistas cambiaron de rumbo y se dirigieron hacia el norte, llegando a las dos de la madrugada al molino de Montón (en el término de Benaguacil), donde pernoctaron ${ }^{50}$.

Al día siguiente se levantaron pronto y, de 9 a 11 de la mañana se dedicaron a robar caballos por los campos y caseríos, para almorzar después en una de las masías de Benaguacil. A continuación se marcharon hacia Pedralba, mientras el alcalde reunía algunos hombres y partía en busca de los rebeldes. Lo mismo hizo el primer regidor de Liria, que se puso al frente de un pequeño grupo de vecinos, acompañado por el juez y cuatro guardias civiles. Poco después se encontró con los rebeldes, que los recibieron a tiros y gritando "iViva Carlos VI!". Pero al oír las descargas los caballos de los carlistas se alborotaron, derribaron a los jinetes y huyeron por los montes, siendo después recuperados por sus dueños, que seguían a la fuerza liberal. El jefe carlista perdió además el sombrero y se dirigió con sus hombres hacia Segorbe para pasar después al Maestrazgo, perseguido por las fuerzas del ejército. Tras este revés los rebeldes se internaron en los montes, dejando por el camino varios efectos que les dificultaban la fuga. Entre ellos se encontraba un saco que contenía una levita con cabos blancos y galones de comandante, así como tres pares de pantalones, un par de zapatos de charol, otro de botas, 23 escudos con las iniciales del preten-

46. Diario Mercantil de Valencia, 12-II-1857.

47. Diario Mercantil de Valencia, 5-IV-1857.

48. Diario Mercantil de Valencia, 16-VI y 3-VII-1857.

49. Archivo General del Ministerio de Asuntos Exteriores y Cooperación, legajo H 2865.

50. Diario Mercantil de Valencia, 29, 31-V y 2, 9-VI-1859. Boletín Oficial de Valencia, 1-VI-1859. 
diente y una corona, unas espuelas, 27 cartuchos de pólvora, 250 cápsulas de pistones y una cartera encarnada sin ningún documento ${ }^{51}$.

Mientras tanto, el juez y sus acompañantes marcharon hacia Pedralba para evitar la entrada de los insurrectos en dicha población ${ }^{52}$. Al mismo tiempo, un grupo de paisanos de Altura, acompañado por los guardias civiles del pueblo, recorrió los montes del término en busca de los fugitivos ${ }^{53}$. A estos grupos se añadió el 29 de mayo el gobernador Bonafós, que acababa de llegar de Madrid y que se reunió con el capitán general, antes de salir en persecución de los carlistas. Para ello recorrió la vega de Valencia y registró algunas cabañas, donde se decía que se encontraba el jefe de la fuerza enemiga, al que no halló. En cambio, sí que encontró carabinas, trabucos, cananas, una cartera con papeles del jefe de la partida y un sombrero hongo de color café, similar al que llevaban todos los rebeldes. Después de esto el gobernador regresó a Valencia (adonde llegó a la una de la madrugada), mientras la fuerza armada seguía persiguiendo a los desbandados. Al mismo tiempo en la capital del Turia eran detenidos siete individuos implicados en este suceso. Durante los dos días siguientes continuaron las batidas para disolver la partida, algo que se acabó logrando, deteniendo a diez de sus integrantes, que fueron puestos a disposición de las autoridades ${ }^{54}$.

Este alzamiento era tan pequeño que debió ser totalmente autónomo, ya que no fue acompañado de revueltas ni de complots en otras partes del país ${ }^{55}$. Por otra parte, la coyuntura económica tampoco era favorable para una nueva rebelión, ya que la expansión económica de los años 50, con un importante desarrollo del ferrocarril y de la agricultura de exportación (con unos precios agrícolas en ascenso $)^{56}$ proporcionaban trabajo y hacían poco atractivo dejarlo todo para unirse a una revuelta con pocas posibilidades de éxito.

51. Diario Mercantil de Valencia, 31 de mayo, 1, 2 y 9 de junio de 1859.

52. Diario Mercantil de Valencia, 9-VI-1859.

53. Diario Mercantil de Valencia, 3-VI-1859.

54. Diario Mercantil de Valencia, 31-V y 2-VI-1859. Boletín Oficial de Valencia, 1-VI-1859.

55. Martínez Gallego sostiene que el alzamiento de 1859 fue una revuelta campesina ante el descontento provocado por la desamortización de Madoz. Al mismo tiempo, afirma que existieron varias partidas carlistas que operaban en la Huerta de Valencia. Pero eso no es lo que se dice en las fuentes que cita (las mismas que he utilizado yo), donde no consta que hubiera más partidas, ni que sus integrantes fueran trabajadores agrícolas, ni que tuvieran ninguna reivindicación en este sentido. Resulta por tanto muy aventurado atribuir un movimiento tan pequeño a un descontento campesino a gran escala, sin más datos que lo sustenten. MARTÍNEZ GALLEGO, Francesc Andreu, Conservar progresando..., pp. 184-186.

56. GARRABOU, Ramón y SANZ FERNÁNDEZ, Jesús, "La agricultura española durante el siglo XIX: ¿Inmovilismo o cambio?” en GARCÍA SANZ, Ángel y GARRABOU, Ramón, 
Más organizado estuvo el alzamiento del año siguiente, cuando los carlistas prepararon una nueva rebelión, aprovechando la guerra con Marruecos y el apoyo del general Jaime Ortega, capitán general de las islas Baleares. El plan inicial era desembarcar en Valencia el 19 de marzo con las tropas del archipiélago, para lo cual se contaba con el apoyo del coronel carlista Manuel Marco, que había reunido algunos partidarios en la capital del Turia y que salía todas las noches a alta mar para recibir instrucciones. Mientras tanto sus hombres se ocupaban en las obras del ferrocarril, esperando órdenes para tomar las $\operatorname{armas}^{57}$.

Por razones que desconocemos, el levantamiento se pospuso ocho días ${ }^{58}$, lo que facilitó que las autoridades se enterasen. El primero que conoció la conspiración fue el embajador español en París, quien el 21 de marzo informó al gobierno que los carlistas estaban preparando un desembarco en Valencia ${ }^{59}$. Las autoridades españolas ordenaron entonces al marqués del Duero que pasara a la capital del Turia, a fin de investigar sobre los rumores que circulaban y sobre su fundamento. Esto llegó a oídos del general Ortega, quien a su vez envió a Valencia a su ayudante Cavero, para enterarse de lo que podía saber el gobierno. Dicho personaje se reunió allí con los dirigentes carlistas Pablo Morales y Hermenegildo Díaz de Cevallos, llegando a la conclusión de que el marqués del Duero estaba al tanto de la trama y que sería sumamente peligroso intentar el desembarco en el Grao, como estaba previsto. Este informe llevó a Ortega a posponer de nuevo el desembarco, trasladándolo ahora a los alrededores de Tortosa $^{60}$. Por lo visto alguien le había comunicado que la región se levantaría en masa en cuanto sus tropas llegaran allí acompañadas por el conde de Montemolin ${ }^{61}$.

El plan se puso en marcha el 1 de abril de 1860, cuando Ortega (acompañado por el pretendiente y varios dirigentes carlistas) desembarcó con sus 4.000 hombres en San Carlos de la Rápita ${ }^{62}$. Y aunque el pronunciamiento fue muy

Historia agraria de la España contemporánea, Barcelona, Crítica, 1985, v. 2, pp. 10, 11 y 36. BURDIEL BUENO, Isabel, "Revolució liberal i moderantisme burgés: 1833-1866" en AA.VV, Història del País Valencià, Barcelona, Editorial 62, 1990, v. 5, p. 115.

57. PIRALA CRIADO, Antonio, Historia contemporánea... v. 2, p. 578. DE JAIME LORÉN, José María y DE JAIME GÓMEZ, José, Manuel Marco y Rodrigo. Marco de Bello, Calamocha, Centro de Estudios del Jiloca, 1992, p. 68.

58. Ibid., p. 68.

59. Archivo General de la Administración, caja 54 / 5579.

60. FERRER, Melchor, ACEDO, José y TEJERA, Domingo, Historia del tradicionalismo... v. 21, p. 125 .

61. Diario Mercantil de Valencia, 12-IV-1860.

62. Archivo General del Ministerio de Asuntos Exteriores y Cooperación, legajo H 2843. Diario Mercantil de Valencia, 7-IV-1860. 
breve y se produjo en el sur de Cataluña, también afectó a las comarcas del norte valenciano, debido a su proximidad geográfica. De hecho, a las dos de la mañana del 2 de abril, 300 rebeldes se presentaron en Vinaroz, ocupando la casa capitular, las puertas de la población y el campanario. A continuación pidieron alojamiento para el resto de la división, que debía llegar por la tarde, así como cien carros y 5.000 raciones de pan. El alcalde, que ignoraba la sublevación, se las suministró, pero una orden repentina hizo salir a la tropa a las tres de la tarde, sin que llegaran a pernoctar allí las fuerzas de Ortega. Poco después llegó a Castellón un capitán de carabineros de la división sublevada, quien dijo que los soldados habían sido engañados y que abandonarían la empresa en cuanto conociesen su objeto ${ }^{63}$.

Al día siguiente llegaron a Morella dos enviados de Ortega, llamados Ramón y Epifanio (a) Morella. Probablemente acudieron a reclamar la entrega de la plaza, pero no consiguieron nada, ya que fueron detenidos inmediatamente por el alcalde ${ }^{64}$. Por aquel entonces la intentona ya había fracasado, debido a la insubordinación de los soldados, que se negaron a respaldar la sublevación. Esto provocó una desesperada huída de los implicados en el movimiento, algunos de los cuales pasaron a tierras valencianas. De esta manera, el 4 de abril llegó a Castellón el ayuda de cámara de Ortega para presentarse a las autoridades. Al mismo tiempo, en Alcalá de Chivert era capturado un teniente coronel, que también era ayudante del general rebelde ${ }^{65}$.

Otro ayudante de Ortega se presentó al alcalde de Benicarló, mientras que el general carlista Elío (que iba de incógnito con la división sublevada) fue capturado por un capitán y cuatro paisanos de Vinaroz, que lo llevaron preso a dicha localidad, para trasladarlo después al castillo de Peñíscola (y de allí a Tortosa). Con él fue capturado su secretario, el comandante Sanz, que también había participado en el alzamiento. Mientras tanto el marqués de La Romana y su hermano eran detenidos en Mogente, abriéndose diligencias contra ellos por sospechas de complicidad en la rebelión carlista ${ }^{66}$.

En previsión de fugas o de nuevos desembarcos, las autoridades de Vinaroz recorrieron las playas en la noche del 6 de abril, con una fuerza de carabineros ${ }^{67}$. Además, los alcaldes del Maestrazgo movilizaron el somatén, a fin de encontrar a los fugitivos que quedaban del alzamiento, entre los que se encontraban el

63. Diario Mercantil de Valencia, 5 y 7-IV-1860.

64. Diario Mercantil de Valencia, 28-IV-1860.

65. Diario Mercantil de Valencia, 7-IV-1860.

66. Diario Mercantil de Valencia, 7, 10, 11, 12-IV y 21-V-1860. Archivo General de la Administración, caja 54 / 5579. CONSTANTE, Carlos, San Carlos de la Rápita (o el conde de Montemolin), Barcelona, La Propaganda Catalana, 1884, pp. 205 y 206.

67. Diario Mercantil de Valencia, 12-IV-1860. 
pretendiente carlista y su hermano. En esta ocasión el norte de la provincia de Castellón se decantó claramente por la reina, ya que no se dio ningún apoyo a la rebelión, sino más bien al contrario. Ayuntamientos, corporaciones, sociedades de todas clases y numerosos ciudadanos acudieron a ofrecerse para acabar con el alzamiento. De todas maneras, en Morella el liberalismo no debía estar muy arraigado, ya que cuando el general Ortega pasó preso por allí, la población se mostró indiferente, en vez de recibirlo con insultos, como hubiera sido lo normal si los vecinos hubieran estado en contra de los carlistas ${ }^{68}$.

Tras la captura de los últimos implicados, el gobierno decretó una amnistía para los encausados y sentenciados por delitos políticos cometidos con posterioridad a 1856, siempre que jurasen fidelidad a la reina ${ }^{69}$. Esto permitió la liberación de casi todos los detenidos, aunque hubo alguno que consiguió escapar sin realizar este trámite. Entre ellos encontramos a Jaime Mur, que en 1839-1840 había sido vicepresidente de la junta de Cabrera y que también estaba complicado en la conspiración. Este personaje se refugió en Amposta y, con la ayuda de un marinero consiguió pasar a Valencia, donde permaneció oculto con Antonio Quintanilla (otro destacado carlista), hasta que pudieron huir a Portugal ${ }^{70}$. Algo parecido sucedió con Manuel Marco, quien, tras esconderse durante un tiempo, acabó regresando a su casa de Bello (Teruel), aprovechando que su intervención no había llegado a ser conocida por las autoridades ${ }^{71}$.

Durante los años siguientes el carlismo pasó por una etapa de crisis, ya que a la muerte del conde de Montemolin le sucedió su hermano don Juan, que tenía ideas más avanzadas y que acabó por reconocer a Isabel $\mathrm{II}^{72}$. De esta manera, los liberales llegaron a darlo por desaparecido y sin posibilidades de recuperarse, ya que a los sucesivos fracasos se unía la falta de un liderazgo claro. Lo mismo debieron pensar muchas personas que anteriormente habían apoyado al carlismo y que aceptaron con resignación el nuevo orden de cosas. Esto se vio claramente el 27 de octubre de 1862, cuando Isabel II y su esposo visitaron Orihuela, que 25 años antes había sido una de las localidades más carlistas del País Valenciano. En esta ocasión no se produjo ningún incidente, sino más bien al contrario, ya que los reyes fueron recibidos y festejados con un entusiasmo indescriptible. Doscientos jóvenes de la huerta, montados a caballo y conduciendo lujosos estandartes, se ofrecieron a la soberana, mientras la

68. Diario Mercantil de Valencia, 15-IV-1860.

69. Archivo General del Ministerio de Asuntos Exteriores y Cooperación, legajo H 2843. Diario Mercantil de Valencia, 4-V-1860.

70. FERRER, Melchor, ACEDO, José y TEJERA, Domingo, Historia del tradicionalismo..., v. 21, p. 153.

71. DE JAIME LORÉN, José María y DE JAIME GÓMEZ, José, Manuel Marco..., p. 70.

72. Diario Mercantil de Valencia, 17-I, 12-IX-1861 y 9-VII-1862. 
muchedumbre la aclamaba, obstruía las calles para verla y arrojaba flores a su paso. Ese día la ciudad estaba abarrotada de personas venidas de toda la comarca, que en número de 30.000 se concentraron para recibir a los reyes. Por la noche varios jóvenes de la ciudad les dieron una serenata y durante el día siguiente los vivas a los monarcas fueron continuos, siendo aclamados de nuevo a las puertas de la catedral ${ }^{73}$.

A la vida de estos hechos, parece evidente que el apoyo al carlismo se había diluido mucho, tanto en el Maestrazgo como en Orihuela, que antaño habían sido los bastiones del tradicionalismo valenciano ${ }^{74}$. Esto no significa que no quedaran carlistas, pero la mayoría de los habitantes de estas zonas ya aceptaba sin problemas a Isabel II y los legitimistas que quedaban habían renunciado ya a hacer nada por la causa, convencidos de que esta no tenía ningún futuro. Sólo algunos exiliados mantenían viva la llama del carlismo, pero sin apenas apoyo en el territorio valenciano.

En cuanto a los neocatólicos, habían criticado duramente la desastrosa intentona de San Carlos de la Rápita, desde las páginas de El Pensamiento Español, uno de sus principales periódicos. Los monárquicos puros afirmaban compartir las mismas ideas que los carlistas, pero no les inspiraba confianza un pretendiente que acababa de perder gran parte de su prestigio en una ridícula tentativa ${ }^{75}$. De esta manera, rechazaron todo alzamiento armado y continuaron con su lucha parlamentaria, para lo que seguían contando con Aparisi y Guijarro como único representante valenciano en Madrid. Tras cinco años de legislatura (la más larga del reinado de Isabel II), se presentó de nuevo a las elecciones en octubre de 1863, siendo reelegido como representante del distrito de Serranos de Valencia, con 253 votos y sin oposición. Al mismo tiempo, el marqués de González, correligionario de Aparisi, fue elegido diputado por Chelva con $122 \operatorname{votos}^{76}$. Curiosamente, en Orihuela la oposición al gobierno no vino de su derecha, sino de su izquierda. De esta manera, en noviembre de 1864 el candidato moderado, Andrés Rebagliato, tuvo que recurrir al fraude electoral para evitar la victoria de Antonio Cánovas, cuya victoria se daba por segura, representando a la Unión Liberal ${ }^{77}$. Nada parecía recordar ya el anterior conservadurismo de los oriolanos.

73. Archivo Histórico de Orihuela, acuerdos del ayuntamiento de 1862-1863, folios 146153. Diario Mercantil de Valencia, 31-X y 1-XI-1862.

74. Sobre la situación política en la Orihuela de esos años véase DÍAZ MARÍN, Pedro y MILLÁN GARCÍA-VARELA, Jesús, "Ante la "marcha al pueblo". El último gobierno de la Unión Liberal en Alicante", Alcores, no 5 (2008), pp. 199 y 201.

75. CANAL, Jordi, El carlismo. Dos siglos de contrarrevolución en España, Madrid, Alianza Editorial, 2000, p. 154.

76. Diario Mercantil de Valencia, 9, 14 y 16-X-1863.

77. Diario Mercantil de Valencia, 22 y 27-IX-1864. 


\section{El acercamiento entre neocatólicos y carlistas}

Durante ocho años el neocatolicismo pareció sentirse integrado en el régimen isabelino, al estar en el poder unos gobiernos moderados y unionistas con los que podía confiar en colaborar para frenar a los movimientos más progresistas de la sociedad de la época. Esta sintonía empezó a romperse en 1864, cuando la promulgación del Syllabus por parte del papado obligó a elegir a los católicos entre su religión y el apoyo al liberalismo ${ }^{78}$. A esto se sumó, en julio de 1865, el reconocimiento del reino de Italia por parte del gobierno español, lo que suponía aceptar la anexión de territorios pontificios y el derrocamiento de monarquías tradicionales por parte del nuevo estado. Esta decisión del gabinete de O`Donnell provocó las protestas de los obispos de Jaca, Santiago, Plasencia y Pamplona, que consideraban sacrílego el nuevo estado, por haberse creado a costa del papado ${ }^{79}$. Además, para Aparisi (y para el resto de los neos) el reconocimiento del reino de Italia suponía "colocar a la nación española en el campo opuesto al catolicismo: en el campo racionalista" 80 . Indignado por esta decisión, el político valenciano perdió toda la confianza que podía tener en los políticos isabelinos y en el propio sistema liberal. Y también por ello decidió retirarse de la vida pública ese mismo mes, en un acto repentino del que dio pocas explicaciones ${ }^{81}$.

Sin embargo, en esta época no hacía falta presentarse para ser elegido diputado, lo que llevó a que Aparisi recibiera un gran número de votos en las elecciones de diciembre. De esta manera, obtuvo 260 sufragios en el distrito del Mar (quedando tercero), 188 en el Mercado (donde quedó primero), 153 en Serranos (también primero) y 167 en San Vicente (en segundo lugar), lo que le permitió ser reelegido como representante valenciano en el Congreso ${ }^{82}$. El político neocatólico agradeció los apoyos, pero renunció al acta de diputado, diciendo que no podía dejar de defender los principios que profesaba ${ }^{83}$. ¿A qué se estaba refiriendo? Pues probablemente a que no podía seguir colaborando con un régimen que aceptaba la amputación de la mayor parte de los Estados Pontificios.

78. CASTRO ALFÍN, Demetrio, "Carlistas y conservadores en el siglo XIX. De Isabel II a la Restauración" en "Por Dios, por la patria y el rey". Las ideas del carlismo, Estella, IV jornadas de estudio del carlismo, gobierno de Navarra, 2010, pp. 64 y 66.

79. Diario Mercantil de Valencia, 8, 11, 16, 18, 21-VII-1865 y 8-IX-1868. URIGÜEN GONZÁLEZ, María Begoña, Origen y desarrollo..., pp. 309, 330, 386, 457, 614 y 620.

80. URIGÜEN GONZÁLEZ, María Begoña, Origen y desarrollo..., p. 492.

81. ROMEO MATEO, M ${ }^{a}$ Cruz, "¿Qué es ser...", p. 162. Diario Mercantil de Valencia, 10VII-1865.

82. Diario Mercantil de Valencia, 4 y 6-XII-1865.

83. Diario Mercantil de Valencia, 21-III y 5-IV-1866. 
Después de estos hechos no parece que hubiera nuevos éxitos electorales de los monárquicos puros, que debieron quedarse sin representante valenciano en el Congreso. Aparisi y Guijarro, cuya salud estaba algo quebrantada, se marchó a los baños de Panticosa ${ }^{84}$ y cuando El Pensamiento Español lo postuló, en enero de 1868, para dirigir el partido, respondió que se había retirado de la vida pública $^{85}$. Probablemente empezara a sentir simpatías por un carlismo al que veía como única garantía del orden tradicional. Y no debía ser el único, ya que el periódico neocatólico La Constancia, afirmó por esas fechas que dejaría de apoyar incondicionalmente al gobierno, como había hecho hasta entonces. También podemos mencionar a Cándido Nocedal, principal jefe del neocatolicismo, que se negó a ocupar ningún cargo en el estado mientras no se anulase el reconocimiento del reino de Italia ${ }^{86}$.

El acercamiento de los neocatólicos al carlismo se aceleró tras la revolución de septiembre de 1868, que provocó el derrocamiento de Isabel II y un giro a la izquierda del régimen liberal. Asustados por el giro que tomaba la situación política española y buscando un claro referente político, muchos monárquicos puros dirigieron sus miradas hacia el pretendiente carlista, que se iba convirtiendo para muchos en el símbolo del orden y de la tradición. De esta manera, a partir de entonces un conjunto de personajes neocatólicos pusieron sus plumas al servicio del carlismo, siendo Aparisi y Guijarro el más destacado de ellos. A esto contribuyó la postura moderada de don Carlos, que aceptó la desamortización y la existencia de unas Cortes, lo que debió ganarle también algunos apoyos entre los liberales más conservadores ${ }^{87}$. De esta manera, el carlismo empezaba a resurgir de sus cenizas, para convertirse en pocos años en un peligroso enemigo del sistema liberal.

84. Diario Mercantil de Valencia, 23-VII-1867.

85. Diario Mercantil de Valencia, 10-I-1868.

86. Diario Mercantil de Valencia, 8-IX-1868.

87. CANAL, Jordi, El carlismo..., pp. 158 y 162. 